Infusionsther Transfusionsmed 1995;22(suppl 2):I-III

\title{
Inhalt, Vol. 22, Suplement 2, 1995
}

10th Meeting of the European Society for Haemapheresis (ESFH) 28. Kongreß der Deutschen Gesellschaft für Transfusionsmedizin und Immunhämatologie (DGTI)

Wien, 17. bis 20. September 1995

ABSTRACTS Kongreßpräsidenten:

B. Blauhut, Linz P. Höcker, Wien

Gastherausgeber:

V. Kretschmer, Marburg

KARGER

Supplement 2, zu Band 22, September 1995

Inf usionstherapie Transfusionsmedizin

Wíssenschaftiicher Beirat

H. Reissigl, Innsbruck

J. Eckart, Augsburg V. Kretschmer, Marburg W. Mempel, München K. Meßmer, München K.

Peter, München W. Stangel, Hannover K.-H. Usadel, Frankfurt

H. Forst, Augsburg B. Zwißler, München

M. Adolph, Augsburg

F.W. Ahnefeld, Ulm

J. Askanazi, New York

C. Baldamus, Köln

H. Bardenheuer, Heidelberg

J.-F. Baron, Paris

W. Behrendt, Aachen

H. Borberg, Köln

U. B. Bruckner, Ulm

R. Eckstein, Erlangen

A. Encke, Frankfurt

U. Finsterer, München

L. Frey, München

Y. Fujita, Okayama

L. Gattinoni, Mailand

M. Georgieff, Ulm

A. Grünert, Ulm

H. J. Gurland, München

P. Hanfland, Bonn

M. Heberer, Basel

J. P. Isbiter, Sydney

K. Jauch, München

W.-P. Kloevekorn, Bad Nauheim

H.-J. Kolb, München 

W. Kox, Berlin
G. C. Kramer, Galveston
H. G. Kress, Wien
B. Kubanek, Ulm
P. Kühnl, Hamburg
H. Laubenthal, Bochum
N. Mutz, Innsbruck
U. E. Nydegger, Bern
W. Oettinger, Trier
Th. Prien, Münster
D. Roelcke, Heidelberg
R. Roos, München
W. Schleinzer, Hamburg
D. Schönitzer, Innsbruck
H.-G. Sieberth, Aachen
U. Suchner, München
L. Sunder-Plassmann, Ulm
E. Wenzel, Homburg/Saar
K. Werdan, Halle/Saale
K. Widhalm, Wien

Supplement 2 zu Band 22, September 1995: ISBN 3-8055-6212-8 Ladenpreis des Sonderheftes: DM 45,- incl. MwSt., Abonnenten erhalten es unberechnet.

Die Zeitschrift erscheint zweimonatlich; pro Jahr erscheint 1 Band zu je 6 Heften.

DGTI-Mitglieder erhalten die Zeitschrift im Rahmen ihrer Mitgliedschaft. Bezugspreis für Jahrgang 22, 1995: DM 173,- I SFr 135,-, einschließlich MwSt., zuzüglich Postgebühren. Der Abonnementpreis ist im voraus zahlbar. Das Abonne-ment der Zeitschrift läuft weiter, wenn es nicht spätestens 4 Wochen vor Abschluß eines Bandes abbestellt wird. Abonnementbestellungen können bei jeder Buch-handlung oder direkt beim Verlag aufgegeben werden:

Übrige Lander: S. Karger AG, Postfach, CH-4009 Basel, Telefon(0 61)3 06 11 11, Fax (0 61) 3 0612 34, E-Mail Karger® Karger.ch

Bundesrepublik Deutschland: S. Karger GmbH, Lörracher Str. 16a, D-79115 Freiburg, Tel. (07 61)45 20 70, Fax (07 61)4 5207 14, Postgiro München 614 40-808.

Anzeigen:

S. Karger, Verlag für Medizin und Naturwissenschaften GmbH, Lörracher Str. 16a, D-79115 Freiburg, Tel. (07 61) 4520 70, Fax (07 61) 452 0714.

Gültig ist die Preisliste Nr. 11 vom 1. Januar 1994.

Für den Inhalt außerhalb des redaktionellen Teiles (insbesondere Anzeigen, Industrieinformationen, Pressezitate und Kongreßinformationen) übernehmen Schriftleitung, Beirat und Verlag keine Gewähr.

Bei dem hier angewandten camera-ready-Verfahren tragen für eventuelle Fehler die Autoren selbst die Verantwortung.

Eine Markenbezeichnung kann warenzeichenrechtlich geschützt sein, auch wenn bei ihrer Verwendung in dieser Zeitschrift das Zeichen ${ }^{\circledR}$ oder ein anderer Hinweis auf etwa bestehende 
Schutzrechte fehlen sollte. Für Satzfehler, insbesondere bei Dosierungsangaben, wird keine Gewähr übernommen.

Die Zeitschrift sowie alle in ihr enthaltenen einzelnen Beiträge und Abbildungen sind urheberrechtlich geschützt. Jede Verwertung, die nicht ausdrücklich vom Ur-heberrechtsgesetz zugelassen ist, bedarf der vorherigen Zustimmung des Verlags. Das gilt insbesondere für Vervielfältigungen, Bearbeitungen, Übersetzungen, Mi-kroverfillmungen und die Einspeicherung und Verarbeitung in elektronischen Sy-stemen. Fotokopien dürfen nur für den persönlichen Gebrauch als Einzelkopien hergestellt werden. Jede im Bereich eines gewerblichen Unternehmens zulässig hergestellte oder benutzte Kopie dient gewerblichen Zwecken gem. § 54(2) UrhG und verpflichtet zur Gebührenzahlung an die Verwertungsgesellschaft WORT, Abt. VG Wissenschaft, Goethestraße 49, D-80336 München.

(C) Copyright 1995 by S. Karger

Verlag für Medizin und Naturwissenschaften GmbH

Lörracher Str. 16a, D-79115 Freiburg

Verlagsleitung und presserechtlich verantwortlich: Sibylle Hopf Assistenz: Susanne Meister

Herstellung: Georg Brunner Anzeigenverwaltung: Christiane Opitz

Satz und Druck: Konkordia Druck GmbH, Eisenbahnstraße 31, D-77815 Bühl

Seite

\section{$\mathrm{AH}$}

Autologe Hämotherapie

1

AL

Albumin

4

$\mathrm{BD}$

Blutspende

5

EP

Erythrozyten: Präparation - Lagerung 7

HL

HLA-System

12

HS

Hämostase

15

IE

Immunhämatologie: Erythrozyten 
IT

Immunhämatologie: Thrombozyten

22

MB

Molekularbiologie

24

PT

Pädiatrische Transfusionsmedizin

26

QU

Qualitätskontrolle

29

ss

Self-Sufficiency

32

VI

Virus: Nachweis - Inaktivierung

34

BS

Biocompatibility-Syde Effects

41

$\mathrm{HC}$

Hemapheresis - Cytokines

43

HR

Hemorheotherapy

44

$\mathrm{PH}$

Photopheresis

45

PP

Plateletpheresis

46 
PS

Platelet: Preparation - Storage

50

PX

Platelettransfusion

55

SA

Stem Cell Pheresis

57

SB

Stem Cell - Bone Marrow

63

TH

Therapeutic Hemapheresis I

65

TPTherapeutic Hemapheresis II68 